Article

\title{
Investigations of the Influence of a Superimposed Oscillation on the Fatigue Strength
}

\author{
Bernd-Arno Behrens, Sven Hübner, Daniel Rosenbusch and Philipp Müller *(D) \\ Institut für Umformtechnik und Umformmaschinen (Institute of Forming Technology and Machines), \\ Leibniz University Hannover, 30823 Garbsen, Germany; behrens@ifum.uni-hannover.de (B.-A.B.); \\ huebner@ifum.uni-hannover.de (S.H.); rosenbusch@ifum.uni-hannover.de (D.R.) \\ * Correspondence: mueller@ifum.uni-hannover.de; Tel.: +49-511-762-4021
}

Received: 10 August 2020; Accepted: 21 September 2020; Published: 23 September 2020

check for updates

\begin{abstract}
Within the scope of the transregional collaborative research centre TCRC73, the effects of an oscillation superimposed forming process for the production of a demonstrator component are investigated. Previous studies in this field were limited to a consideration of the process-related parameters such as the influence of the plastic work and the friction or the component-related parameters such as the influence of the surface quality and the mold filling. This research concentrates on the consideration of the mechanical vibration resistance of components that were manufactured superimposed oscillated. For this purpose, Wöhler tests are conducted in which the fatigue strength of superimposed oscillation pre-stretched test samples and oscillation-free pre-stretched test samples are investigated. First, Wöhler curves are generated in the tensile threshold range for tensile samples made out of the steels DC04 and DP600. Subsequently, tensile specimens are pre-stretched superimposed oscillated and oscillation-free. These specimens are subjected to a tensile threshold load until they break. The influence of the superimposed oscillation forming on the long-term fatigue of components is derived from the comparison of the bearable load cycles. Investigations of the microstructure of the specimens are conducted in order to draw conclusions about the influence on the long-term strength.
\end{abstract}

Keywords: pre-strain; superimposed oscillation; fatigue strength

\section{Introduction}

The influence of pre-stretching on the fatigue strength of various types of steel has been investigated in previous studies. For example, Zhao et al. found an intensifying extension of the fatigue strength in the range of numbers of cycles to failure $\left(\mathrm{N}_{\mathrm{f}}\right)>10^{4}$ for tensile specimens made of SAPH 440 steel with increasing pre-stretching. This effect was attributed to an increase in pre-stretched induced dislocation density in microscopic mechanism, which lead to a higher static and fatigue strength [1]. Ha et al. attributed an improvement in tensile and fatigue strength after a pre-stretching due to deformation [2]. Other researchers found an increase in fatigue strength also in interstitial-free (IF) [3], twinning induced plasticity (TWIP) [4], dual phase (DP) [5] and transformation induced plasticity (TRIP) [6] steels due to pre-stretching. Shang et al. described an improved fatigue life for steel wheels made of DP600 due to an increased residual stress [7]. Especially in the area of $\mathrm{N}_{\mathrm{f}}>10^{5}$ load cycles, a significant enhance in fatigue strength with growing pre-stretching was recorded [8,9]. Previous studies have also investigated the influence of a superimposed oscillated forming on material-related effects. For example, Izumi et al. found a change in dislocation movements that explains a decrease in the average forming force caused by a superimposed oscillation [10]. Furthermore, Liu et al. observed an oscillation-induced change in the flow behavior of dislocation movements and an oscillation substantiated grain refinement [11]. However, the effects of superimposed oscillated forming on the tensile and fatigue strength of components are still largely unexplored. 
Since the high potential of superimposed oscillated-forming processes on effects such as increasing the surface quality [12] and improving the form-filling [13] of components has been demonstrated in previous studies, this technology has promising application possibilities. Especially in the new technology of sheet-bulk metal forming, which aims at the production of complex functional components with secondary forming elements made of thin sheets [14], superimposed oscillated forming offers the interesting possibility of extending the production limits of this technology. In this research, the influence of a superimposed oscillated pre-stretching on the fatigue strength of tensile specimens made of the materials DC04 and DP600 is investigated. For this purpose, non-pre-stretched tensile specimens are first tested in fatigue tests until failure. Subsequently, oscillation-free and superimposed oscillation pre-stretched tensile specimens are tested for their fatigue strength. The corresponding fatigue strength curves are recorded and compared. In addition, hardness measurements are conducted on the pre-stretched specimens in order to draw conclusions about work-hardening mechanisms. The specimens are examined microscopically to obtain material-related influences on the fatigue strength. The aim of this research is to gain a deeper understanding of the influence of a superimposed oscillation-forming process on the fatigue and tensile strength of components.

\section{Materials and Methods}

The Wöhler test or fatigue test is a suitable experiment for determining fatigue strength [15]. In this test, samples are subjected to a load amplitude at constant middle stress until fracture. The number of load cycles until specimen break is plotted in a diagram over the stress amplitude applied. The experiments are performed on the resonance pulser Testronic (max. force: $150 \mathrm{kN}$ ) by the company Rumul AG, Neuhausen am Rheinfall, Switzerland (see Figure 1). Tension specimens with a cross-sectional area of $25 \mathrm{~mm}^{2}$ are cut out in the rolling direction from $2 \mathrm{~mm}$ thick sheets by water jet cutting. In order to prove that the cutting edge does not provide an unnecessarily large region of attack for crack propagation, it is measured on an optical measuring macroscope VR3200 of the company Keyence, Osaka, Japan. The image of a cutting edge as well as the sample geometry is shown in Figure 1. A good cutting quality is demonstrated.
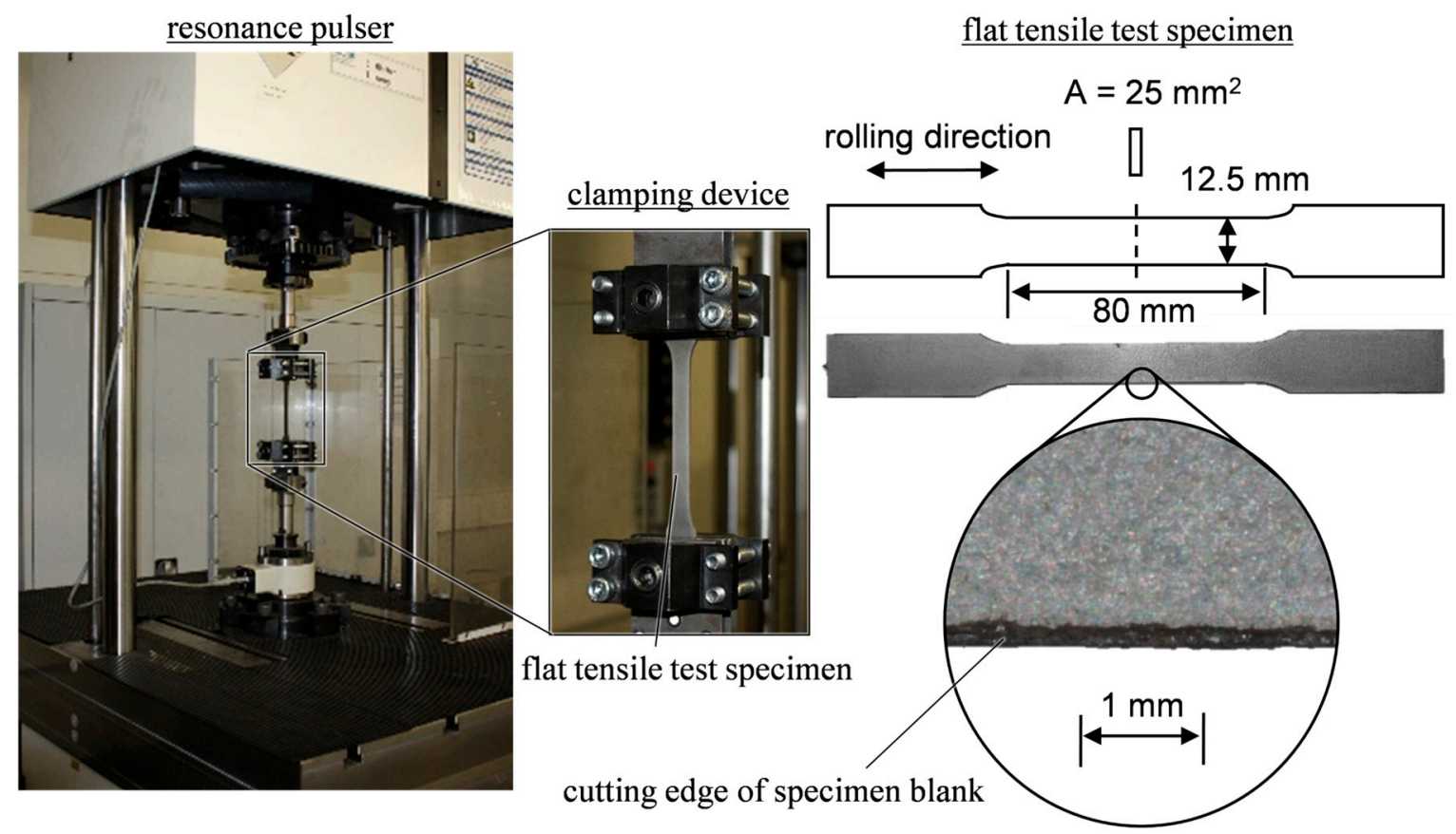

Figure 1. Experimental stand for fatigue tests and sample geometry. 
The sample materials used are the ferritic deep-drawing steel DC04 and the two-phase steel DP600, which mainly consists of a ferritic structure with martensitic inclusions. These materials are selected because of their significantly different mechanical properties and industrial relevance. DC04 has a tensile strength of 270 to $350 \mathrm{MPa}$ [16], while DP600 has a tensile strength of 580 to $670 \mathrm{MPa}$ [17] in the delivery condition. In addition, both materials have different chemical compositions, as shown in Table 1. Thus, cross-material effects can be observed for superimposed oscillated forming.

Table 1. Chemical components of DC04 [16] and DP600 [17].

\begin{tabular}{cccccccc}
\hline Material & C & Si & Mn & P & S & Al & Cr + Mo + Ni \\
\hline DC04 & $0.08 \%$ & - & $0.4 \%$ & $0.03 \%$ & $0.03 \%$ & - & - \\
\hline DP600 & $0.14 \%$ & $1.5 \%$ & $2.0 \%$ & $0.07 \%$ & $0.015 \%$ & $0.015 \%$ & $1.0 \%$ \\
\hline
\end{tabular}

The samples are divided into three classes for each steel (see Table 2). The first class refers to tensile specimens without further pre-treatment in the condition as delivered by the steel manufacturer Salzgitter Flachstahl GmbH, Salzgitter, Germany. The second class designates specimens that are pre-stretched by a length change of $15 \%$ at the resonance pulser without superimposed oscillation. For this purpose, the specimens are clamped on each side with two mechanical clamping jaws and drawn until the final geometry is reached. The third class designates specimens that are pre-stretched superimposed oscillated by a length change of $15 \%$ at the resonance pulser. The superimposed oscillation on the average tensile stress has a stress amplitude of $\sigma_{\mathrm{A}}=40 \mathrm{MPa}$ and a frequency of $\mathrm{f}=90 \mathrm{~Hz}$.

Table 2. Sample classes for fatigue tests.

\begin{tabular}{ccc}
\hline Material & Pre-Treatment & Sample Class \\
\hline \multirow{2}{*}{ DC04 } & oscillation-free pre-stretched (15\%) & $\mathrm{A}$ \\
\cline { 2 - 3 } & superimposed oscillation pre-stretched (15\%) & $\mathrm{B}$ \\
\cline { 2 - 3 } & delivery state & $\mathrm{C}$ \\
\hline \multirow{2}{*}{ DP600 } & oscillation-free pre-stretched (15\%) & $\mathrm{D}$ \\
\cline { 2 - 3 } & superimposed oscillation pre-stretched (15\%) & $\mathrm{E}$ \\
\cline { 2 - 3 } & delivery state & $\mathrm{F}$ \\
\hline
\end{tabular}

After pre-treatment, the samples are clamped at the resonance pulser and subjected to a fatigue test. The loading takes place in the tensile threshold range. A constant middle stress of $\sigma_{\mathrm{m}}=160 \mathrm{MPa}$ is applied to the DC04 samples. For the DP600 samples, a constant middle stress of $\sigma_{\mathrm{m}}=460 \mathrm{MPa}$ is applied. The samples are tested in a tensile test to determine the tensile strength. The samples are subjected to different amplitudes at constant average stress until they break. The average load cycles until fracture are plotted in a diagram over the amplitude applied. Hardness measurements are conducted on all six sample types. The grain structure is examined microscopically to obtain conclusions about the material related-effects influencing the fatigue strength. The experiments are conducted at room temperature.

\section{Results}

In the following chapter, the results of the fatigue tests are presented with the fatigue strength curves, micrographs of the grain structure, and hardness measurements. First, the fatigue strength curves for the different materials and pre-stretches are evaluated. In addition, a metallographic examination of the pre-stretched and non-pre-stretched specimens is conducted. For this purpose, micrographs of the grain structure and hardness measurements are carried out. 


\subsection{Fatigue Life Cycles and Tensile Strength}

The flat-tensile specimens are tested for their tensile strength in a uniaxial tensile test. The tensile strength of the material DC04 is $295 \mathrm{MPa}$ for the samples without pre-treatment. At a pre-strain of $15 \%$ without superimposed oscillation, a tensile strength increase to $334 \mathrm{MPa}$ is measured. Furthermore, a superimposed oscillation pre-stretching of $15 \%$ leads to an increase in tensile strength to $326 \mathrm{MPa}$. Thus, the tensile strength for quasi-statically pre-stretched DC04 specimens is slightly higher than for the oscillation-superimposed pre-stretched specimens. For the DP600 specimens without pre-treatment, the tensile strength is $595 \mathrm{MPa}$. At a pre-strain level of $15 \%$, the tensile strength of oscillation-free pre-strained DP600 specimens increases to $640 \mathrm{MPa}$. A superimposed oscillated pre-stretching of $15 \%$ leads to an increase in tensile strength up to $642 \mathrm{MPa}$. The results of the fatigue tests for the samples made of the material DC04 are shown in Figure 2. The results of the fatigue tests for samples made of the material DP600 are shown in Figure 3.

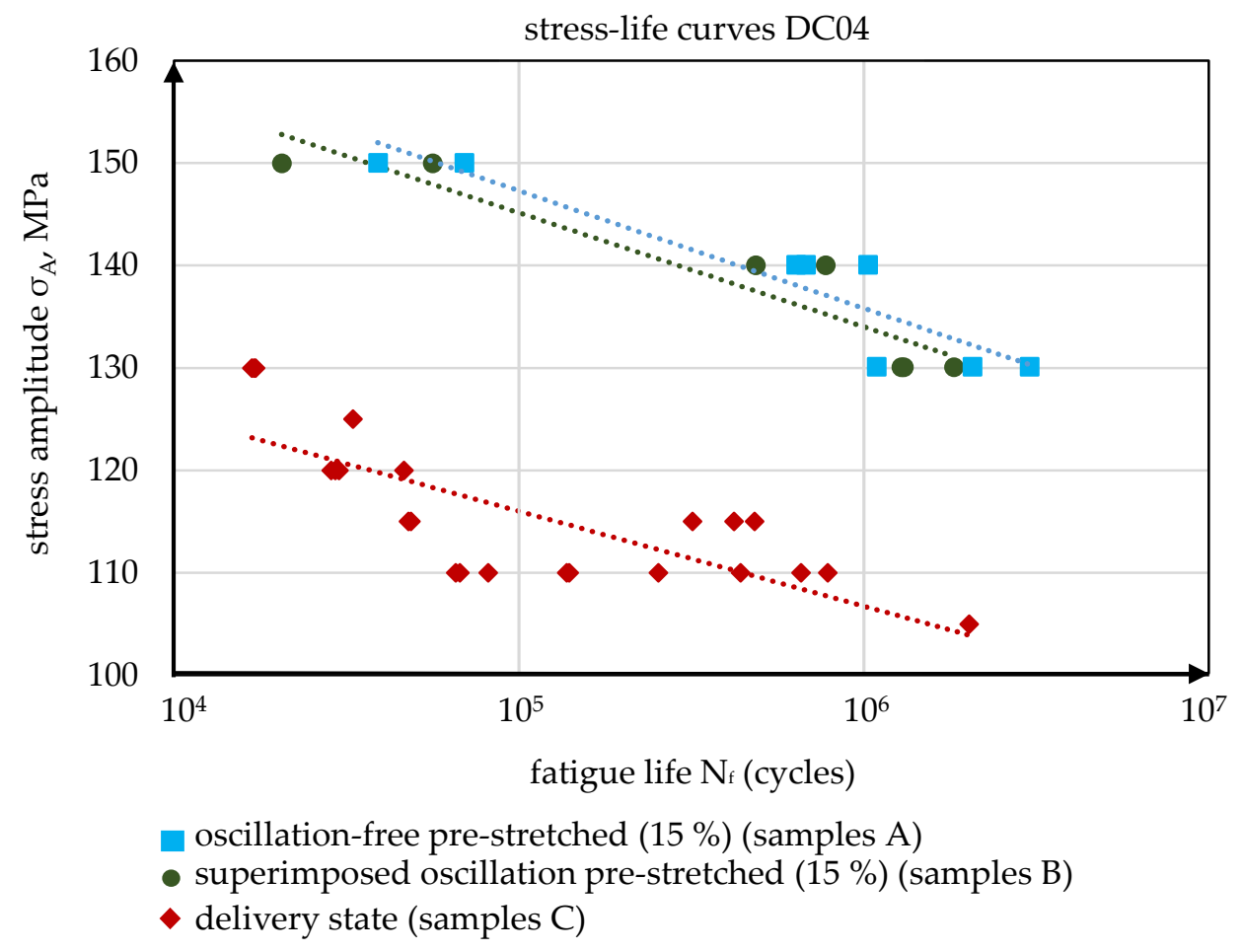

Figure 2. Stress-life curves for flat-tensile test specimens made out of DC04. 


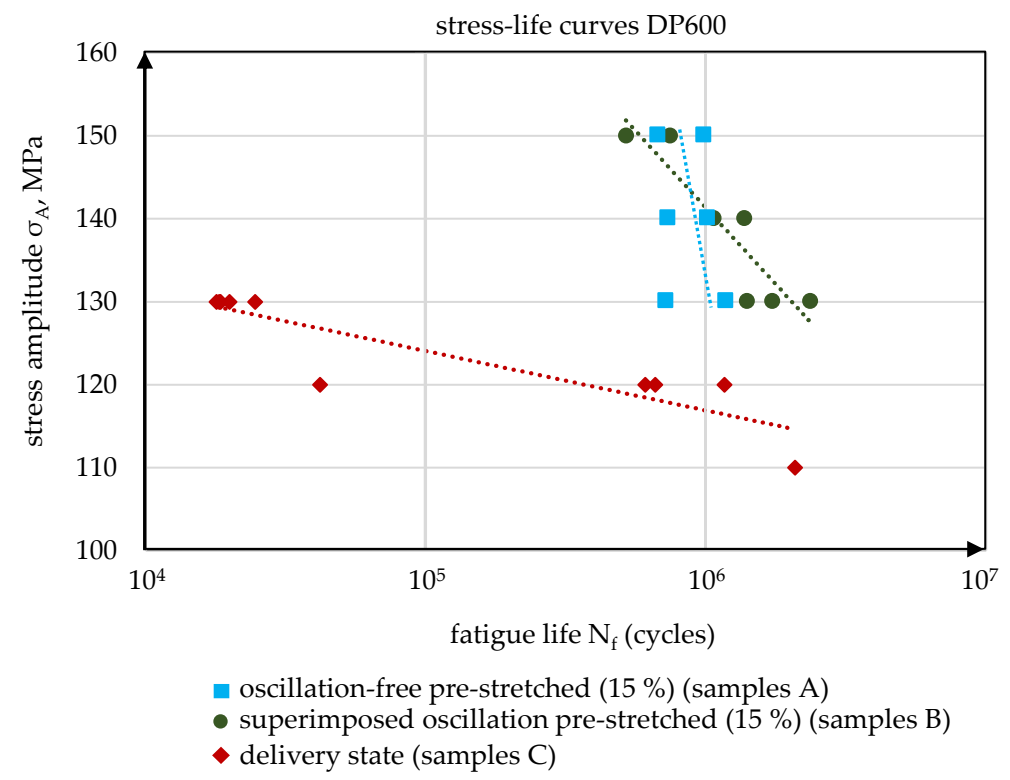

Figure 3. Stress-life curves for flat-tensile test specimens made out of DP600.

The fatigue strength curves are determined by trend lines from the diagrams. The trend lines are shown in Figures 2 and 3. The lines are described mathematically by the following formulae in Table 3. The formulas were obtained by drawing the compensation lines between the experimental determined points:

Table 3. Mathematical course of the trend lines.

\begin{tabular}{ccc}
\hline Sample & Formula & Number \\
\hline DC04 delivery state & $\sigma_{\mathrm{A}}=-4.82 \ln \left(\mathrm{N}_{\mathrm{f}}\right)+175.11$ & $(1)$ \\
\hline DC04 15\% oscillation-free pre-stretched & $\sigma_{\mathrm{A}}=-5.125 \ln \left(\mathrm{N}_{\mathrm{f}}\right)+206.64$ & $(2)$ \\
\hline DC04 15\% superimposed oscillation pre-stretched & $\sigma_{\mathrm{A}}=-5.095 \ln \left(\mathrm{N}_{\mathrm{f}}\right)+204.5$ & $(3)$ \\
\hline DP600 delivery state & $\sigma_{\mathrm{A}}=-3.994 \ln \left(\mathrm{N}_{\mathrm{f}}\right)+170.29$ & $(4)$ \\
\hline DP600 15\% oscillation-free pre-stretched & $\sigma_{\mathrm{A}}=-35.69 \ln \left(\mathrm{N}_{\mathrm{f}}\right)+628.85$ & $(5)$ \\
\hline DP600 15\% superimposed oscillation pre-stretched & $\sigma_{\mathrm{A}}=-15.4 \ln \left(\mathrm{N}_{\mathrm{f}}\right)+352.81$ & $(6)$ \\
\hline
\end{tabular}

The evaluation of the fatigue test curves shows that the fatigue strength of both the DC04 and the DP600 samples increases with pre-stretching. This confirms the results from previous studies [9]. For the DC04 specimens, the average fatigue strength at an amplitude of $130 \mathrm{MPa}$ increases from approximately $N_{f}=17,000$ for sample $C$ specimens to approximately $N_{f}=2,062,700$ for sample A specimens. With a superimposed oscillated pre-stretching of the sample B specimens, the average fatigue strength of the DC04 specimens increases to approximately $N_{f}=1,285,900$. The fatigue strength lines, which are shown as trend lines in Figure 2, run almost parallel for all three types of DC04 specimens. A superimposed oscillated pre-stretching for the DC04 samples leads to a reduction of the fatigue strength compared to the oscillation-free pre-stretched samples. A possible pre-loading of the specimens due to the superimposed oscillation pre-stretching can be declared as an explanation for this phenomenon. The superimposed oscillated forming of the specimen could promote fatigue phenomena in the material, such as enhanced void growth, which leads to a reduction of the fatigue life.

For the DP600 specimens, the average fatigue strength at an amplitude of $130 \mathrm{MPa}$ increases from approximately $\mathrm{N}_{\mathrm{f}}=19,840$ for sample $\mathrm{F}$ to approximately $\mathrm{N}_{\mathrm{f}}=1,181,100$ for sample $\mathrm{D}$. For sample E, the average fatigue strength of the DP600 specimens increases at an amplitude of $130 \mathrm{MPa}$ to approximately $\mathrm{N}_{\mathrm{f}}=1,408,000$. Compared to the DC04 specimens, the fatigue strength lines for the 
DP600 specimens are steeper when the material is pre-stretched. For sample D, the fatigue strength line is steeper than that for sample E (see Figure 3). As a result, the fatigue strength in the range of approximately $\mathrm{N}_{\mathrm{f}}<900,000$ is higher for sample D specimens than for sample E specimens. This is confirmed by the tensile strength measurements, which show a slightly higher value at $642 \mathrm{MPa}$ for the sample D specimens than for the sample E specimens with a value of the tensile strength of $640 \mathrm{MPa}$. For load cycles beyond $\mathrm{N}_{\mathrm{f}}=900,000$, a superimposed oscillation in pre-stretching for DP600 specimens leads to an increase in fatigue strength compared to oscillation-free pre-stretched specimens. A steeper course of the fatigue strength line due to pre-stretching has already been observed by Zhao et al. [1]. For DP600, this can be explained by a reduction in ductility as a result of work-hardening mechanisms due to pre-stretching. A superimposed oscillated pre-stretching leads to a reduction in fatigue strength for higher stress amplitudes for the DP600 specimens. Similar to the DC04 specimens, this can be explained by a possible pre-loading of the specimens due to a superimposed oscillated pre-stretching. Since the fatigue strength is higher for lower stress amplitudes for superimposed oscillated pre-stretched specimens than it is for the oscillation-free pre-stretched DP600 specimens, the pre-loading introduced into the material DP600 seems to be less critical for failure in the range of lower stress amplitudes.

\subsection{Metallographics}

Hardness measurements are conducted. The evaluation of the hardness measurements is shown in Figure 4. Hardness is measured according to the Vickers test method with a test load of $9.807 \mathrm{~N}$ at six positions on the specimens (see Figure 4). Three samples per set of parameters were measured. The DC04 specimens have a hardness of $98 \pm 2 \mathrm{HV}$ in the delivery condition. For the sample B specimens, the hardness increases to $136 \pm 3 \mathrm{HV}$, and for the sample A specimens, the hardness increases to $131 \pm 2 \mathrm{HV}$. According to Hance, strain hardening increases with increasing pre-stretching [18]. Since the sample B specimens have a hardness of 3.6\% higher than the sample A specimens, it is assumed that the superimposed oscillation leads to increased strain hardening. This can be explained by oscillation-induced incremental movements in the material, which superimpose the global material movement during forming. Due to the superimposed oscillation, the DC04 specimens deform more strongly at the microstructure level, which leads to the increased pre-loading of the material. Oscillation-induced pre-load explains the lower fatigue strength for the superimposed oscillated pre-stretched DC04 specimens in Figure 2.

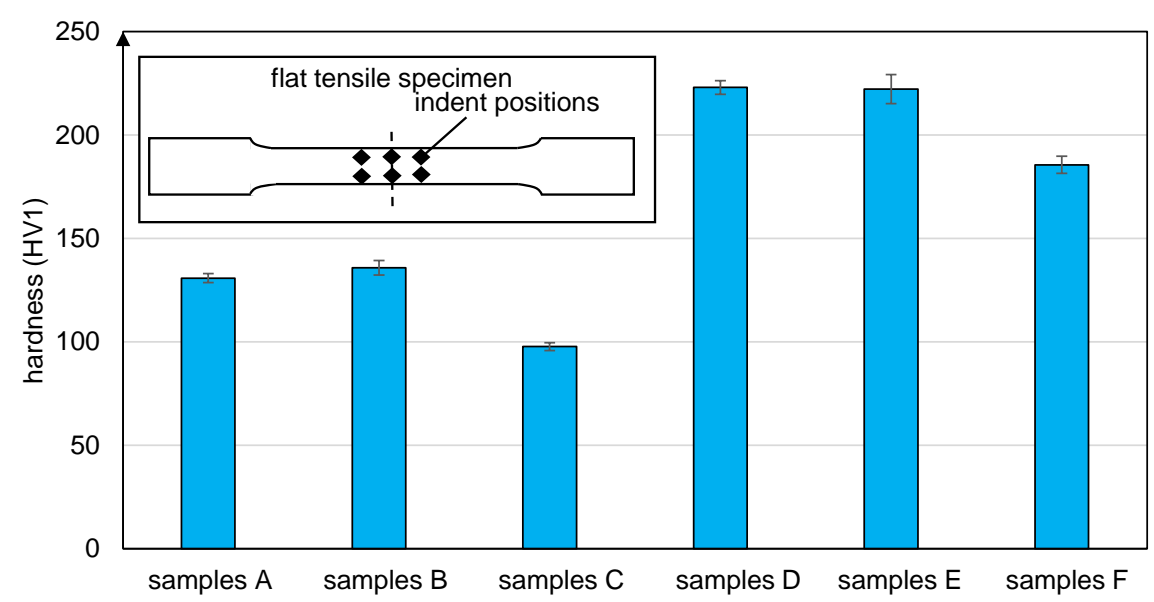

Figure 4. Hardness values for DC04 and DP600 flat tensile specimen in delivery state and superimposed oscillated and oscillation-free $15 \%$ pre-stretched levels.

The DP600 specimens have a hardness of $186 \pm 4 \mathrm{HV}$ in delivery conditions. For the sample E specimens, the hardness increases to $222 \pm 7 \mathrm{HV}$, and for the sample D specimens, the hardness increases to $223 \pm 3 \mathrm{HV}$. In contrast to the DC04 specimens, the DP600 specimens show no significant difference in strain-hardening for superimposed oscillated and oscillation-free pre-stretched specimens. 
In addition to the observations from the fatigue tests, a superimposed oscillation during forming causes different effects in both materials. Any oscillation-induced pre-load occurring in the material is not noticeable in the DP600 specimens by considering the strain hardening. The curves of fatigue strength for the sample D and sample E specimens are not as clearly separated from each other as the fatigue strength curves of the DC04 specimens. Thus, it can be assumed that the influence of the superimposed oscillation for the pre-stretching of the DP600 specimens shows lower impact.

Figure 5 shows light microscopic microstructure images for the six sample types. Grain size and grain orientation are visualized by light microscopy. For the superimposed oscillated pre-stretched DC04 specimens, a more elongated microstructure can be seen than for the oscillation-free pre-stretched DC04 specimens. This confirms the assumption that deformation at the microstructure level is enhanced by incremental oscillation-induced movements in the DC04 samples. Thus, superimposed oscillation favors the material flow for DC04. Deviations in the forming behavior in a superimposed oscillation forming between DC04 and DP600 material have already been determined in previous studies [19] but are not yet fully clarified. For the DP600 specimens, no differences in grain size and grain orientation can be detected for oscillation-free and superimposed oscillated pre-stretched specimens. This can be explained by the fact that the microstructure of the DP600 material with martinsitic inclusions is less sensitive to the incremental load cycles of a superimposed oscillation. Since the load amplitude of $40 \mathrm{MPa}$ for the superimposed oscillated forming was the same for both DC04 and DP600, it can be assumed that the harder DP600 material does not react as strongly to the superimposed oscillation as the softer DC04 material. This is confirmed by the observation from the hardness measurements, which suggests a reduced influence of the superimposed oscillation forming on the material properties of the DP600 samples.

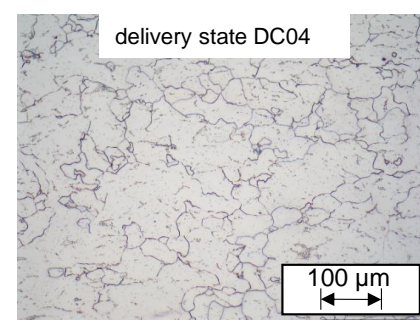

a.)

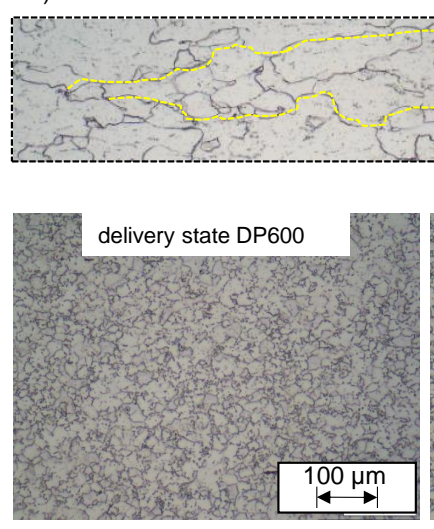

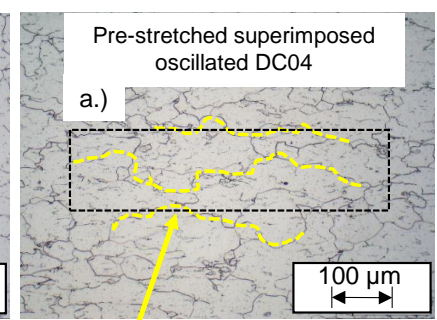

b.)

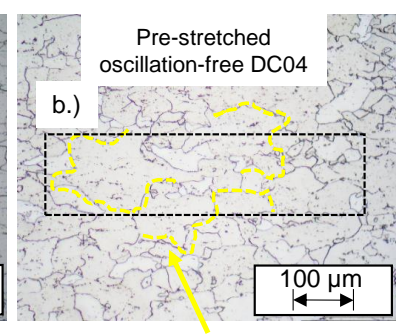

more globular grains
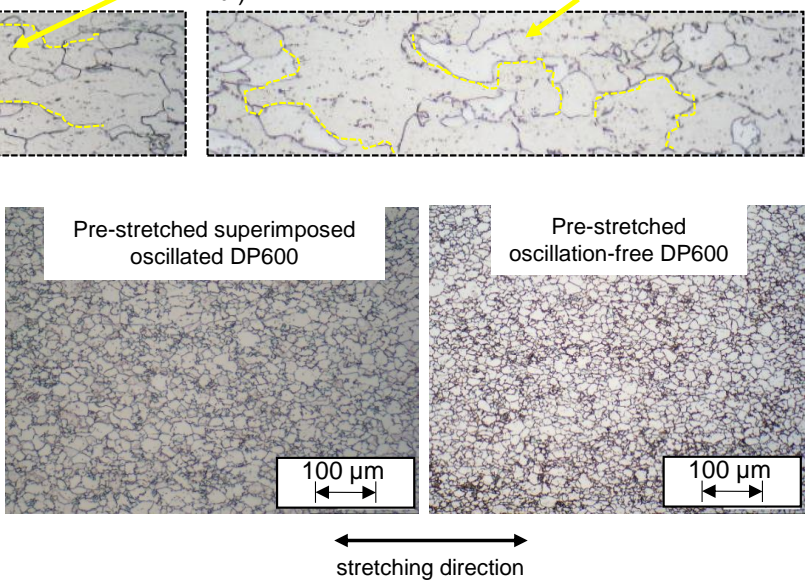

Figure 5. Micrographs for superimposed oscillation and oscillation-free pre-stretched and non-prestretched tensile test specimen.

\section{Discussion}

In this research, the effects of a superimposed oscillated pre-stretching on the fatigue strength, strain hardening, and structural properties of tensile test specimens made of the materials DC04 and DP600 were investigated. Since a superimposed oscillation has a high potential according to an 
extension of forming limits [13], a better understanding of the effects of a superimposed oscillation on the fatigue strength and strain hardening is of high importance. It was found that the fatigue strength behavior, strain hardening, and the influence on the microstructure of the materials DC04 and DP600 can be influenced differently by a superimposed oscillation. For DC04, there is a slight trend to a reduction in fatigue strength due to a superimposed oscillated pre-stretching compared to an oscillation-free pre-stretching. This is explained by an oscillation-induced pre-load of the DC04 steel. The incremental movements superimposed on the global movement during the forming process in the material also lead to a strain hardening in the DC0 4 that is increased by about 3.6\%. The influence of a superimposed oscillation can also be seen in microstructure images in the DC04 by an enhanced stretching of the grains. Therefore, a tendency toward higher strain hardening correlates with a more deformed microstructure in the DC04 samples. The relation between higher structural deformation and higher strain hardening is known from the literature [20]. It is of interest that this effect occurs primarily on the microstructure scale in this research, since the total strain (of 15\%) is the same for superimposed oscillated and oscillation-free pre-stretched samples.

For DP600, the fatigue strength curves for superimposed oscillated and oscillation-free pre-stretched specimens lay closer together, whereas the fatigue strength curve for superimposed oscillated pre-stretched specimens is steeper. The influence of a superimposed oscillation on the strain hardening and the microstructure of DP600 is not apparent in the current investigations. This can be explained by the martinsitic inclusions in DP600, which lead to a higher basic hardness of the material. This leads to a higher resistance against oscillation-induced movements in DP600 steel for the investigated amplitude range. Kalashami et al. found that for DP steels, the microstructure deformation occurs in several steps. At relatively low loads, the ferritic phase deforms first, while the martinsitic phase remains intact [21]. Therefore, it is assumed that the superimposed oscillation may have induced an effect in the ferritic phase of the microstructure without being apparent on the microscopic image. This effect could be responsible for the flatter course of the stress-life curve of the superimposed oscillated formed DP600 samples. In the case of hardness measurements, the values for the superimposed oscillated and oscillation-free formed samples are almost in the same order, so no concrete conclusions can be drawn. To investigate this suspected influence, more experiments should be carried out in future works.

Therefore, the different material-dependent influences on superimposed oscillated forming processes are very interesting and require deeper investigations. Furthermore, the oscillation-induced increased strain hardening of the DC04 steel shows potential for further investigations. In addition, the influence of a superimposed oscillation on the fatigue strength of the DP600 steel can be investigated in more detail in further studies. Especially in the field of long-term strength, the DP600 steel shows potential.

\section{Conclusions}

In summary, the following conclusions can be derived from the results of this research:

(1) The fatigue strength of tensile test specimens increases significantly for the steels DC04 and DP600 with a pre-stretching of 15\%. This is due to enhanced strain hardening caused by forming.

(2) A superimposed oscillation shows different effects on the forming behavior of steels that differ greatly in their mechanical and structural properties.

(3) For DC04, strain hardening increases slightly with a superimposed oscillated uniaxial forming, while the fatigue strength slightly decreases. This is explained by an enhanced deformation on microstructural scale and a simultaneous preloading of the material.

(4) For DP600, the long-term strength increases for uniaxial superimposed oscillated pre-stretched samples in comparison to uniaxial oscillation-free pre-stretched samples.

(5) The stress-life curve flattens when the flat-tensile test specimens made of DP600 are pre-stretched superimposed oscillated. 
Especially for the dual-phase steel, the mechanisms of the oscillation-induced effects in the microstructure should be investigated in more detail in future studies because of the potential of increasing the long-term strength.

Author Contributions: Conceptualization, methodology, software, formal analysis, investigation, visualization, data curation and writing — original draft preparation, P.M.; validation, S.H. and B.-A.B.; resources, S.H. and B.-A.B.; writing-review and editing, D.R., S.H. and B.-A.B.; supervision, B.-A.B.; project administration, S.H.; funding acquisition, B.-A.B. All authors have read and agreed to the published version of the manuscript.

Funding: The authors gratefully acknowledge the financial support of the German Research Foundation (DFG) within the transregional collaborative research center TCRC73 "Manufacturing of complex functional components with variants by using a new sheet metal forming process-Sheet Bulk Metal Forming" project A7-116817829 ("Dynamic Process Forces").

Conflicts of Interest: The authors declare no conflict of interest.

\section{References}

1. Zhao, L.-H.; Cai, H.-C.; Weng, S.; Zheng, S.-L. Effect of pre-strain on the fatigue behavior of SAPH440 steel. Mater. Express 2019, 9, 1001-1008. [CrossRef]

2. Ha, D.W.; Jeong, C.Y. Effect of pre-straining on the high-cycle fatigue properties of hot-rolled steel sheets for automotive structural uses. Korean J. Met. Mater. 2018, 56, 177-186.

3. Yan, B.; Belanger, P.; Citrin, K. Effect of forming strain on fatigue performance of a mild automotive steel. SAE Trans. 2001. [CrossRef]

4. Kim, Y.W.; Kim, G.; Hong, S.-G.; Lee, C.S. Energy-based approach to predict the fatigue life behavior of pre-strained Fe-18Mn TWIP steel. Mater. Sci. Eng. A 2011, 528, 4696-4702. [CrossRef]

5. Le, Q.; Kang, H.-T.; Kridli, G.; Khosrovaneh, A.; Yan, B. Modified strain-life equation to consider the effect of different prestrain paths for dual phase sheet steel. J. Mater. Process. Technol. 2009, 209, 3525-3531. [CrossRef]

6. Song, S.M.; Sugimoto, K.I.; Kandaka, S.; Futamura, A.; Kobayashi, M.; Masuda, S. Effects of pre-straining on high cycle fatigue strength of high strength low alloy TRIP steels. J. Soc. Mater. Sci. Jpn. 2001, 50, 1091-1097. [CrossRef]

7. Shang, D.; Liu, X.; Shan, Y.; Jiang, E. Research on the stamping residual stress of steel wheel disc and its effect on the fatigue life of wheel. Int. J. Fatigue 2016, 93, 173-183. [CrossRef]

8. Hu, Z.; Zhu, P.; Meng, J. Fatigue properties of transformation-induced plasticity and dual-phase steels for auto-body lightweight: Experiment, modeling and application. Mater. Des. 2010, 31, 2884-2890. [CrossRef]

9. Munier, R.; Doudard, C.; Calloch, S.; Weber, B. Towards a faster determination of high cycle fatigue properties taking into account the influence of a plastic pre-strain from selfheating measurements. Procedia Eng. 2010, 2, 1741-1750. [CrossRef]

10. Izumi, O.; Oyama, K.; Suzuki, Y. Effects of Superimposed Ultrasonic Vibration on Compressive Deformation of Metals. Trans. Jpn. Inst. Met. 1966, 7, 162-167. [CrossRef]

11. Liu, Y.; Suslov, S.; Han, Q.; Hua, L.; Xu, C. Comparison between Ultrasonic Vibration-Assisted Upsetting and Conventional Upsetting. Met. Mater. Trans. A 2013, 44, 3232-3244. [CrossRef]

12. Koch, S.; Vučetić, M.; Hübner, S.; Bouguecha, A.; Behrens, B.-A. Superimposed Oscillating and Non-Oscillating Ring Compression Tests for Sheet-Bulk Metal Forming Technology. Appl. Mech. Mater. 2015, 794, 89-96. [CrossRef]

13. Behrens, B.-A.; Hübner, S.; Müller, P.; Besserer, H.-B.; Gerstein, G.; Koch, S.; Rosenbusch, D. New Multistage Sheet-Bulk Metal Forming Process Using Oscillating Tools. Metals 2020, 10, 617. [CrossRef]

14. Merklein, M.; Allwood, J.M.; Behrens, B.-A.; Brosius, A.; Hagenah, H.; Kuzman, K.; Mori, K.; Tekkaya, A.E.; Weckenmann, A. Bulk forming of sheet metal. CIRP Ann. Manuf. Technol. 2012, 61, 725-745. [CrossRef]

15. Schott, G.; Donat, B.; Schaper, M. The consecutive wöhler curve approach to damage accumulation. Fatigue Fract. Eng. Mater. Struct. 1996, 19, 373-385. [CrossRef]

16. Salzgitter Flachstahl. Produkt Information, Cold Rolled Steel DC04; Salzgitter Flachstahl: Salzgitter, Germany, 2014.

17. Salzgitter Flachstahl. Produkt Information, Cold Rolled Steel DP600; Salzgitter Flachstahl: Salzgitter, Germany, 2014.

18. Hance, B.M.; Foley, R.P.; Matlock, D.K. Effect of Strain Path on Formability and Microstructural Evolution in Low-Carbon Sheet Steels. SAE Trans. 1997, 106, 193-204. 
19. Behrens, B.-A.; Meijer, A.; Stangier, D.; Hübner, S.; Biermann, D.; Tillmann, W.; Rosenbusch, D.; Müller, P. Static and oscillation superimposed ring compression tests with structured and coated tools for Sheet-Bulk Metal Forming. J. Manuf. Process. 2020, 55, 78-86. [CrossRef]

20. Antoine, P.; Vandeputte, S.; Vogt, J.-B. Effect of Microstructure on Strain-hardening Behaviour of a Ti-IF Steel Grade. ISIJ Int. 2005, 45, 399-404. [CrossRef]

21. Kalashami, A.G.; Kermanpur, A.; Ghassemali, E.; Najafizadeh, A.; Mazaheri, Y. Correlation of microstructure and strain hardening behavior in the ultrafine-grained $\mathrm{Nb}$-bearing dual phase steels. Mater. Sci. Eng. A 2016, 678, 215-226. [CrossRef]

(C) 2020 by the authors. Licensee MDPI, Basel, Switzerland. This article is an open access article distributed under the terms and conditions of the Creative Commons Attribution (CC BY) license (http://creativecommons.org/licenses/by/4.0/). 